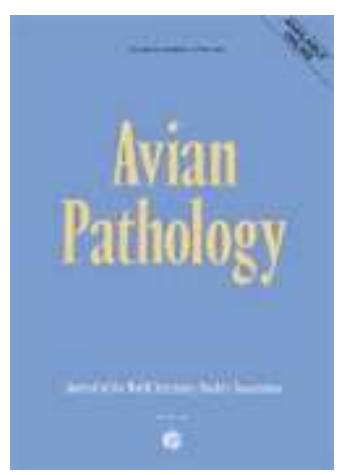

\title{
Safety and efficacy of an inactivated Carbopol-adjuvanted Goose haemorrhagic polyomavirus vaccine for domestic geese
}

\begin{tabular}{|c|c|}
\hline Journal: & Avian Pathology \\
\hline Manuscript ID: & CAVP-2009-0191 \\
\hline Manuscript Type: & Original Research Paper \\
\hline $\begin{array}{r}\text { Date Submitted by the } \\
\text { Author: }\end{array}$ & 14-Dec-2009 \\
\hline Complete List of Authors: & $\begin{array}{l}\text { GELFI, Jacqueline; Ecole Nationale Veterinaire de Toulouse, UMR } \\
1225 \text { IHAP } \\
\text { PAPPALARDO, Michael; Ecole Nationale Veterinaire, IHAP } \\
\text { CLAVERYS, Carine; Ecole Nationale Veterinaire de Toulouse, UMR } \\
1225 \text { IHAP; Ecole Nationale Veterinaire, IHAP } \\
\text { PERALTA, Brigitte; Ecole Nationale Veterinaire, IHAP } \\
\text { GUERIN, Jean-Luc; Ecole Nationale Veterinaire, Pathologie aviaire } \\
\text { et porcine }\end{array}$ \\
\hline Keywords: & goose, polyomavirus, vaccine, carbopol \\
\hline
\end{tabular}

\section{SCHOLARONE Manuscripts}


Please use the Figures and Table at the end of this version, NOT VIA MANUSCRIPT CENTRAL

Safety and efficacy of an inactivated Carbopol-adjuvanted Goose haemorrhagic polyomavirus vaccine for domestic geese

\section{Jacqueline Gelfi $^{1,2}$, Michael Pappalardo ${ }^{1,2}$, Carine Claverys ${ }^{1,2}$, Brigitte Peralta ${ }^{1,2}$ and Jean-Luc Guerin ${ }^{1,2^{*}}$}

${ }^{1}$ INRA, UMR 1225, F-31076 Toulouse, France

${ }^{2}$ Université de Toulouse ; ENVT ; UMR 1225 ; F-31076 Toulouse, France

Short title: an inactivated carbopol GHPV vaccine for geese

* To whom correspondence should be addressed:

Ecole Nationale Vétérinaire de Toulouse

23, chemin des capelles 31076 Toulouse Cedex 3, France

Phone: +33561 193258

Fax: +33 561193924

E-mail: jl.guerin@envt.fr

Received: 31 July 2009 


\section{Summary}

Hemorrhagic Nephritis Enteritis of the goose (HNEG) is an epizootic viral disease in domestic geese. The causal agent is a polyomavirus, namely Goose haemorrhagic polyomavirus (GHPV). To help control the disease, an inactivated vaccine was developed, based on viral particles produced in goose kidney cells. Viral material was quantified using real-time quantitative PCR, inactivated with $\beta$-propiolactone and adjuvanted with Carbopol, an acrylic acid polymer. Carbopol proved to be more immunogenic than aluminum hydroxide and was totally safe when administered to young goslings and breeders alike. Carbopoladjuvanted vaccine induced a high serological response. Moreover, goslings hatched from vaccinated breeders were protected against viral challenge, indicating that maternally-derived neutralizing antibodies (MDA) were efficiently transferred. MDA were still detectable 15 days post-hatch. Clinical trials will be necessary to accurately evaluate a vaccine-based HNEG control strategy under field conditions. 


\section{Introduction}

Hemorrhagic Enteritis Nephritis of the goose (HNEG) is a viral infection in domestic geese, first described in 1970 in Hungary (Bernath \& Szalai, 1970). It was later reported in France and Germany (Schettler, 1977; Kisary, 1993; Guérin, 2008). The causative agent of HNEG was isolated and identified in 2000 and was the first polyomavirus to be considered as pathogenic in poultry (Guérin et al., 2000). This virus, namely GHPV (Goose haemorrhagic polyomavirus), is clearly divergent from the other polyomaviruses identified so far. As a nonenveloped DNA virus, it is highly resistant to heat, desiccation and lipid solvents (Shah, 1996; Guérin, 2008). During spontaneous or experimental infections, the clinical picture includes lameness and nervous signs and, at necropsy, lesions due to nephritis and oedema. Histologically, necrosis of endothelial cells and lymphocyte depletion in the cloacal bursa are a classic picture (Lacroux et al., 2004). Infection seems widespread in the field, affecting fattening goslings as well as breeders; carriage is asymptomatic in birds over 13 weeks of age (Palya et al., 2004; Guérin, 2008). Recently, GHPV infection has been described in Muscovy and mule ducks, without apparent association with specific clinical signs (Pingret et al., 2008). When facing outbreaks of HNEG, biosecurity measures alone are not sufficient to control the disease. Vaccination of geese might be a solution, applied either to growing goslings or their parents. Even if clinical signs occur mostly after 4 weeks of age, infection may actually begin in the very early life of the birds. As the immune status of neonate goslings may be critical in HNEG control, vaccination of breeders may contribute to the protection of their offspring, as shown for Avian Polyomavirus (APV) infections in psittacines (Ritchie et al., 1996). Attempts to produce GHPV viral-like particles (VLP) based on the VP1subunit have been described and applied to the production of antigen for 
serological assays (Zielonka et al., 2006) and recently as a subunit vaccine for goslings (Mato et al., 2009). This vaccine was preliminarily assayed in goslings and showed to elicit some protection.

In this article, we describe the production of GHPV antigen, the preparation of a Carbopol-adjuvanted inactivated vaccine and the first safety and immunogenicity trials in geese. We also present the ELISA assay designed to measure serological response. Finally, the efficacy of this vaccine was assessed in day-old goslings hatched from vaccinated geese.

\section{Materials and Methods}

Cells and virus. A stock of Goose haemorrhagic polyomavirus (GHPV), strain Toulouse 2000, was grown in goose kidney (GK) cells, derived from a day-old gosling. This viral strain has been described previously (Guérin et al, 2000) and the sequence of its major capsid protein VP1 gene has been deposited in GenBank under the accession number AF226991. These cells were cultivated at $37^{\circ} \mathrm{C}$ in DMEM with $10 \%$ foetal calf serum and were permissive to GHPV infection as previously shown (Guérin et al., 2000). Optimized conditions of viral production were determined: briefly, after $2 \mathrm{~h}$ adsorption at $39^{\circ} \mathrm{C}$, the viral inoculum was removed and infected cells were incubated in DMEM with $10 \%$ foetal calf serum for 7 days at $39^{\circ} \mathrm{C}$. After 3 freeze-thaw cycles, suspensions were centrifuged to remove cells debris and stored as virus stock at $-80^{\circ} \mathrm{C}$ until use.

\section{Detection and quantification of GHPV DNA using either classical or quantitative PCR.}

In all vaccination or challenge experiments, tissues (i.e. spleen and kidney) or cloacal swabs were sampled and stored at $-20^{\circ} \mathrm{C}$ until DNA extraction, using the High pure PCR template Preparation kit (Invitrogen). PCR amplification was performed as previously described, using 
the set of primers VP1F (5'-GAGGTTGTTGGAGTGACCACAATG-3') and VP1R (5' ACAACCCTGCAATTCCAAGGGTTC-3') (Guérin et al., 2000). PCR products were analyzed by electrophoresis on a $1.5 \%$ agarose gel. A PCR product was cloned into a pGEMT plasmid vector (Stratagene ${ }^{\circledR}$ ), amplified, purified and finally quantified by $260 / 280$ OD spectrophotometry. Serial dilutions of this plasmid were subsequently used as standard for real-time PCR analysis. In order to quantify the viral load in virus stock, a SYBR ${ }^{\circledR}$ Green quantitative PCR (qPCR) assay was performed using the same set of primers as described above. Briefly, reaction mixes were obtained by combining $12.5 \mu 1$ of $2 \times \mathrm{SYBR}^{\circledR}$ Green MasterMix (Applied Bio Systems) and $2.5 \mu 1$ of each primer, used at a final concentration of $500 \mu \mathrm{M}$. Real time PCR was performed on a GeneAmp 9700 cycler, using the following programme: $5 \mathrm{~min}$ at $95^{\circ} \mathrm{C}$, then 40 cycles of $15 \mathrm{~s}$ at $95^{\circ} \mathrm{C}$ and $1 \mathrm{~min}$ at $60^{\circ} \mathrm{C}$. For each reaction, the Cycle threshold $(\mathrm{Ct})$ value, corresponding to the number of cycles required for the fluorescence intensity graph to cross threshold, was determined and quantification was performed by reference to a standard VP1-pGEMT plasmid. In order to assess the specificity of PCR products, a dissociation curve was generated after the last PCR cycle, resulting in an expected melting temperature $(\mathrm{Tm})$ of $78.6^{\circ} \mathrm{C}$.

Vaccine preparation. After real-time PCR titration, the virus stock was used for vaccine preparation. Inactivation of GHPV was performed according to the procedure described for Avian Polyomavirus (Ritchie et al., 1996). Briefly, the virus supernatant was incubated for $12 \mathrm{~h}$ at room temperature with $0.2 \% \beta$-propiolactone (Sigma), after which $\mathrm{pH}$ was adjusted to 7.0 and $\beta$-propiolactone was added to a final concentration of $0.3 \%$. After $2 \mathrm{~h}$ incubation, the preparation was neutralized with $40 \mathrm{mM}$ Sodium thiosulfate. Complete inactivation was certified by indirect immunofluorescence test $48 \mathrm{~h}$ post inoculation (p.i.) on a GK monolayer, using a post-infectious anti-GHPV goose serum and a secondary goat anti-duck serum (KPL) 
(Guérin et al., 2000). PCR detection was also performed to confirm the destruction of GHPV DNA. After inactivation, antigen stock was used for preparation of experimental vaccines, adjuvanted with either Aluminum Hydroxide $\left(\mathrm{Al}(\mathrm{OH})_{3}\right)$ or a carbomer.

$\mathrm{An} \mathrm{Al}(\mathrm{OH})_{3}$-adjuvanted vaccine (Called $\mathrm{Al}-\mathrm{Vac}$ later in the paper) was prepared using a $\mathrm{Al}(\mathrm{OH})_{3}$ aqueous gel (Alhydrogel $2 \%^{\mathrm{TM}}$, Superfos), gently mixed with the antigen stock at a final load of $12.5 \mathrm{mg} / \mathrm{mL}$. Each dose was adjusted to a final volume of $0.5 \mathrm{~mL}$.

A Carbopol-adjuvanted vaccine (called Carbo-Vac later in this paper) was prepared using $2 \mathrm{mg}$ per dose of Carbopol 934 ${ }^{\mathrm{TM}}$, an acrylic acid polymer (Noveon Pharma) mixed with the antigen stock. Each dose was adjusted to a $0.5 \mathrm{~mL}$ final volume.

Vaccination of goslings. Goslings were supplied from a local hatchery and came from flocks without any history of HNEG during the growing period, and PCR negative for GHPV (data not shown). They were housed in BSL-2 facilities. In a first assay, 3 batches of five goslings each were administered an $\mathrm{Al}(\mathrm{OH})_{3}$-adjuvanted vaccine containing respectively $10^{9}, 10^{10}$ or $10^{11}$ genomes per dose twice, at 3 and 6 weeks of age. Goslings were bled at weeks 3, 6 and 9 and their sera tested by ELISA for antibodies.

A second trial was performed on 3 separated groups of five birds each: one group was non-vaccinated (control group), the second group received a $0.5 \mathrm{~mL}$ dose of Al-Vac twice and a third group received a $0.5 \mathrm{~mL}$ dose of Carbo-Vac vaccine twice. At day of vaccination and 2, 4, 6 and 7 weeks post-vaccination, the birds were bled and their sera collected for testing by ELISA.

At the end of the two trials, birds were killed and their kidneys were sampled and submitted to real-time PCR analysis in order to further confirm the complete inactivation of GHPV in the vaccines. 
Vaccination of breeders. Three hundred future breeder geese, housed in conventional facilities, were shown to be free of GHPV, as well as GHPV-specific antibodies, on the basis of an ELISA and a real time PCR analysis performed on the sera of 30 birds. The birds received a subcutaneous injection of Carbo-Vac, 6 weeks and 2 weeks before the beginning of the laying period. Ten females were identified as non-vaccinated controls and maintained together with the vaccinated birds. All male geese were also vaccinated. At day 56 postvaccination, 20 vaccinated females randomly sampled in the flock and the 10 non-vaccinated control birds were bled and their sera collected for ELISA testing. A cloacal swab was collected from each bird for subsequent PCR detection of GHPV DNA. Eggs laid from either vaccinated or non-vaccinated geese were identified distinctively for subsequent study of their offspring. Throughout all the experiments, vaccinated birds were monitored daily for 50 days for their behaviour, food intake, weight, egg production and hatchability and were also subjected to a complete clinical examination.

ELISA method. An ELISA was developed by adapting procedures routinely used in the laboratory (Gelfi et al., 1999). For this purpose, semi purified GHPV antigen was prepared as follows: monolayers of GK cells were infected with GHPV stock at $39^{\circ} \mathrm{C}$ for 4 to 6 days in DMEM with $10 \%$ foetal calf serum. When cytopathic effect reached $100 \%$, the supernatant was collected and clarified by centrifugation at $3000 \mathrm{~g}$ to remove cells debris. Virus was then pelleted by ultracentrifugation at $100,000 \mathrm{~g}$ for $2 \mathrm{~h}$. Pellets were suspended in nanopure water with protease inhibitors and the optical density (OD) was read at 260 and 280nm. The purity of the preparation was determined by an OD ratio 260/280 of roughly 1,2 . Correlation between OD and qPCR quantification was established through 5 independent assays: $1 \mathrm{OD}$ at $280 \mathrm{~nm}$ corresponded to $3 \times 10^{10}$ viral genomes $/ \mathrm{ml}$ of viral suspension. 
To perform the ELISA, 96-well microplates were coated overnight at $37^{\circ} \mathrm{C}$ with semipurified GHPV particles corresponding to $5 \times 10^{7}$ genomes/well, diluted in PBS buffer. The wells were washed 3 times in PBS, blocked by incubation for $1 \mathrm{~h}$ with $15 \mathrm{mg} / \mathrm{mL}$ gelatin in PBS buffer and then incubated with serial 2-fold dilutions of the serum sample in duplicate. Positive and negative standards were included in each plate. Wells were washed 3 times in PBS- $0.05 \%$ Tween 20 buffer, and then incubated with a 1:100 dilution of goat anti-duck IgY conjugated with alkaline phosphatase (KPL). Finally, after 3 washes in PBS-0.05\% Tween 20 and one in PBS, detection was performed using PNPP (P-NitroPhenyl Phosphate) as substrate and absorbance was read in a spectrophotometer (wavelength: $405 \mathrm{~nm}$ ). To determine cut-off value for positivity, the sera of 10 goslings sampled before vaccination were pooled as standard negative control. Each negative serum was first individually tested at a dilution of 1:20. ELISA titres were expressed as the inverse of the dilution giving an OD value 3 times as great as the OD value of the standard negative control. For the ELISA titration in egg yolk, IgY were purified using a commercial kit "Eggcellent Chicken IgY Purification Kit" (Pierce, Rockford, Illinois, USA). The purified fraction was resuspended in a volume of buffer corresponding to the volume of egg yolk processed for extraction. Aliquots were frozen at $20^{\circ} \mathrm{C}$ and later processed for ELISA testing as described above.

Viral challenge and serological study on day-old goslings. Fifteen day-old goslings hatched from eggs laid by the experimental breeders flock at day 56 post vaccination, were housed in BSL-2 facilities, according to the guidelines of the European Community on Animal Care (European Council directive 3086/609/ECC, 24 November 1986), in wire-floored cages with infrared lamps for heating, and were provided with food and water ad libitum. These 15 birds were inoculated by the subcutaneous route with $200 \mu 1$ of GHPV inoculum (strain Toulouse 2000), purified from cell culture as previously described (Guérin et al., 2000). This inoculum 
corresponded to $10^{7}$ genome-equivalent viruses, as determined by real-time quantitative PCR analysis. Fifteen goslings hatched from a non-vaccinated flock were used as controls, 5 birds were inoculated with $10^{7}$ genome-equivalent GHPV, using the same protocol and 10 goslings were mock-infected. The 3 batches of birds were housed separately. All birds were clinically monitored on a daily basis. At 8 days p.i. all the birds which were still alive were submitted to a cloacal swab sampling and screened for GHPV DNA. Finally, either at spontaneous death during the experiment or when killed at day 20 p.i., all birds were submitted to a complete post mortem examination and sampled for real-time PCR analysis of kidney and spleen tissues.

Fifteen goslings hatched from eggs laid at day 56 post-vaccination by vaccinated breeders and 15 hatched from eggs laid by non-vaccinated breeders, were bled and weighed at 1, 5, 10 and 15 days of age and their serum collected for ELISA testing.

\section{Results}

Preparation of GHPV vaccines. GHPV was produced in optimized conditions in GK cells as described above. Virus production was then quantified by real-time PCR and inactivated with $\beta$-propiolactone. Virus inactivation was confirmed by three successive passages in GK cells and immunofluorescence assay. Results show a good quantification with a viral suspension of up to $5 \times 10^{11}$ genomes $/ \mathrm{ml}$ and a complete efficiency of the inactivation procedure.

Carbopol adjuvant is immunogenic in geese. In a first attempt, the antigen load was optimized by means of a comparison of $\mathrm{Al}(\mathrm{OH})_{3}$-adjuvanted vaccines containing $10^{9}, 10^{10}$ or $10^{11}$ genomes per dose, respectively. The curve measuring serological response showed that 
the highest antibody titre was obtained with the vaccine containing $10^{10}$ genomes of GHPV (Figure 1a). This dose was therefore used for all the following trials of vaccines, adjuvanted with either $\mathrm{Al}(\mathrm{OH})_{3}$ or Carbopol.

In a second step, we compared Carbopol and classical $\mathrm{Al}(\mathrm{OH})_{3}$ as adjuvants. Two groups of 5 goslings each were inoculated with a vaccine adjuvanted with either $\mathrm{Al}(\mathrm{OH})_{3}$ or Carbopol in accordance with the protocol described above. Based on ELISA assays, the Carbopol-adjuvanted vaccine induced a significantly stronger serological response as early as after the first injection, the difference being 4-fold at day 49 (Figure 1b). This experiment was repeated twice with the same result. Based on all these findings, the subsequent vaccination assays were based on a Carbopol-adjuvanted vaccine containing an antigenic load corresponding to $10^{10}$ genome-equivalent GHPV / GHPV-equivalent genome.

\section{The Carbopol vaccine induces a strong serological response in growing goslings and}

breeder geese. To evaluate Carbo-Vac safety and immunogenicity, goslings were vaccinated twice with a 3-week time interval between the two injections (Figure 2). Vaccinated goslings showed a rapid seroconversion. In both vaccinated and control birds, cloacal swabs remained PCR negative throughout the study. In particular, no vaccinated bird presented any viral carriage detectable by PCR. The breeders were challenged in order to assess immunogenicity and transmission of maternal antibodies (MDA) to goslings. In a first attempt, a serological analysis was performed at day 56 post vaccination, without follow-up of the serological kinetics. Indeed, a significant amount of specific antibodies was detected in the geese sera, in the vitellus of eggs and in the serum of their offspring (Figure 3).

Both Al-Vac and Carbo-Vac vaccines are totally innocuous in goose. No local inflammatory reaction at the point of injection was noticed during any of the experiments 
described. During the vaccination assays in both young goslings and future breeders, the health status of the animals never altered and food intake remained in accordance with standards. Vaccination of future breeders had no effect on their laying performance or on the hatchability of embryonated eggs.

Transmission and decay of maternally-derived antibodies. The objective of the breeders' vaccination scheme is the passive transfer of MDA from vaccinated geese to goslings through the vitellus. To evaluate this transmission, 15 goslings hatched from the vaccinated breeder geese in the previous experiment were monitored for 15 days. These goslings were hatched from eggs laid at day 56, i.e. 5 weeks after the second vaccination. The average antibodies titre in these goslings was 330 at day-old, then decreased rapidly to the level of the controls by 15 days. In the same period, the goslings' weight had increased five fold (Figure 4).

\section{Goslings hatched form vaccinated breeders are protected against viral challenge. Viral} challenge was performed on 15 one-day-old goslings hatched from vaccinated breeders and 10 day-old goslings hatched from non-vaccinated breeders. Five day-old goslings hatched from non-vaccinated breeders were not challenged as controls. The results of the challenge are shown in Table 1. Goslings hatched from vaccinated breeders showed neither clinical signs suggestive of HNEG, nor detectable GHPV infection after a virulent challenge at oneday-old.

\section{Discussion}

Polyomaviruses infect mammals and birds but, to date, avian species are the only host in which polyomaviruses show a significant pathogenicity. Within the family Polyomaviridae, 
these inflammatory features are highly specific of avian polyomaviruses (APV) (Johne \& Muller, 2007). Vaccination was implemented for the control of APV infections in psittacines, with a significant efficacy. By contrast, attempts to vaccinate humans against polyomaviruses infections, such as JC, have been poorly investigated since these viruses affect immunocompromised hosts only.

Propagation of GHPV was successfully performed in GK cells derived from a day-old gosling, which allowed the production of significant amounts of viral particles (Guérin et al., 2000). Culture medium and procedures were optimized to produce a high and reproducible amount of viral material (data not shown). In our hands, these kidney cells allow the production of a significant viral yield on a routine basis, corresponding to up to $10^{11} \mathrm{GHPV}$ genomes/ml of culture supernatant. Intriguingly, GHPV propagation could not be obtained by other groups with primary kidney cells (Johne \& Muller, 2003). This discrepancy may be related to specific properties of the GK cell seed obtained in our laboratory or, alternatively, an adaptation of the GHPV strain Toulouse 2000 to cell culture.

The quantification of viral yield was performed indirectly using real-time PCR, since plaque titration in GK cells seldom gives a clear cytopathic effect. Virus titration on goose embryo was previously described but this method is time consuming and can hardly be applied to routine titration of GHPV (Bernath et al., 2006). We developed a quantitative PCR assay to obtain an indirect quantification of the virus. The correlation between the number of genome copies and the viral particles was described for SV40 (Simian virus 40) and showed to be reliable in this model (Shi et al., 1999). The same procedure was used in all the experiments described in this study.

Alternatively, recombinant VP1 may be used for the purpose of serological assays or vaccination. Indeed, recombinant VP1 was shown to induce a serological response and provide protection to goslings after vaccination once at day-old, or twice by boosting at 18 
days of age (Mato et al., 2009). These results confirm that VP1 is the major antigenic determinant of polyomaviruses and can be expressed in subunit or vectored vaccines. Furthermore, recombinant proteins can easily be quantified, allowing a control of antigenic load. However, in a field perspective, the marketing of such a recombinant vaccine would be severely restricted by the European licensing regulation applied to biologicals based on genetically modified organisms.

Among the common poultry species, the goose is, by far, the most sensitive to adjuvant-associated general secondary reactions. We therefore had to find an alternative adjuvant to the oil-based ones routinely used in poultry vaccines. Since the $\mathrm{Al}(\mathrm{OH})_{3^{-}}$ adjuvanted vaccine offered very poor immunogenicity, Carbopol polymer was assayed, according to previous uses in horses (Mumford et al., 1994; Minke et al., 2007), swine and pigeons (Vereecken et al., 2000). The adjuvant properties of polyacrylic acids, designated by the term carbomers, may vary greatly with the number of carboxyl groups present in the final molecule. Here we have shown that Carbopol 934 is actually immunogenic and may be a relevant alternative to oil in avian species for which safety is a major concern. However, it would be of interest to further study the efficacy of Carbopol 934 in poultry, by comparison with other carbomers and oil emulsions; some trials are under way in our group to address this. The most challenging issue is the duration of the serological response, since the antibody response is well known for being weaker and shorter in waterfowl than in chickens (Higgins, 1996). This problem recently arose in the vaccination campaign of ducks against highly pathogenic influenza virus H5N1 (Steensels et al., 2009). Further trials will be necessary to assess a protective response during a whole laying period of breeder geese, even though in this species the laying period is remarkably short (i.e. less than 6 months), compared to other poultry breeders. The transmission of MDA through the vitellus has been confirmed here. This transmission is supposed to be restricted to the complete forms of IgY, i.e. excluding the 
truncated $\Delta \mathrm{Fc} \mathrm{IgY,} \mathrm{which} \mathrm{are} \mathrm{much} \mathrm{more} \mathrm{abundant} \mathrm{in} \mathrm{the} \mathrm{serum} \mathrm{of} \mathrm{breeders} \mathrm{(Liu} \mathrm{\&} \mathrm{Higgins,}$ 1990). This uncommon mechanism, specific to waterfowl species, may explain the apparent discrepancy between ELISA titres observed in our study in breeders and day-old goslings respectively.

Infection of breeders seems to be highly prevalent in geese flocks (Palya et al., 2004). Within an infected flock, a great variability is classically encountered, inducing heterogeneity in transmission of MDA to their offspring (Guérin et al., unpublished data). These discrepancies may lead to rolling infections in brooding flocks. Beside transmission of MDA, vaccination of breeders induces a strong humoral response, which may prevent an active infection during the laying period and subsequently, spreading of the virus either through faecal contamination of the shell or via a still-to-demonstrate vertical route. In this perspective, vaccination of breeders should contribute to a global control of HNEG in the goose industry. Vaccination of growing goslings will have to be applied in order to supplement the decaying MDA in the case of strong viral challenge. Long-term field applications of GHPV vaccine will be required to accurately evaluate a vaccine-based HNEG control strategy.

\section{Acknowledgements}

We gratefully thank our colleagues Benoit Severac, Stéphane Bertagnoli and Christelle Camus-Bouclainville for their helpful suggestions and careful reading of the manuscript. This work was supported by Régions Aquitaine and Midi-Pyrénées, CIFOG (Comité Interprofessionnel des Palmipèdes à Foie Gras) and OFIVAL (Office Interprofessionnel des Viandes, de l'Elevage et de l'Aviculture). 


\section{References}

Bernáth, S., Farsang, A., Kovács, A., Nagy, E. \& Dobos-Kovács, M. (2006). Pathology of goose haemorrhagic polyomavirus infection in goose embryos. Avian Pathology, 35, 49-52.

Bernath, S. \& Szalai, F. (1970). Investigations for clearing the etiology of the disease appeared among goslings in 1969. Magyar Allatorvosok Lapja, 25, 531-536.

Gelfi, J., Chantal, J., Thanh Phong, T., Py R. \& Boucraut-Baralon C. (1999). Development of an ELISA for detection of myxoma virus-specific rabbit antibodies: test evaluation for diagnostic applications on vaccinated and wild rabbit sera. Journal of Veterinary Diagnostic Investigation, 11, 240-245.

Guérin, J-L. (2008). Hemorrhagic Nephritis Enteritis of Geese. In: Y.M. Saif, (Ed), Diseases of Poultry, 12th edn (pp. 393-396). Ames: Iowa State University Press.

Guérin, J-L., Gelfi, J., Dubois, L., Vuillaume, A., Boucraut-Baralon, C. \&. Pingret, J-L. (2000). A novel polyomavirus (Goose haemorrhagic polyomavirus) is the agent of Hemorrhagic Nephritis Enteritis of Geese. Journal of Virology, 74, 4523-4529.

Higgins, D.A. (1996). Comparative immunology of avian species. in T.F. Davison, T.R. Morris \& L.N. Payne (Eds) Poultry Immunology, Poultry Science Symposium Series volume 24 (pp. 149-205). Abingdon: Carfax.

Johne, R. \& Muller, H. (2003). The genome of Goose haemorrhagic polyomavirus, a new member of the proposed subgenus Avipolyomavirus. Virology, 308, 291-302.

Johne, R. \& Muller, H. (2007). Polyomaviruses of birds: etiologic agents of inflammatory diseases in a tumor virus family. Journal of Virology, 81, 11554-11559.

Kisary J. (1993). Haemorragic Nephritis and Enteritis of Geese. p. 513-514. In : J.B. Mc Ferran \& M.S. Mc Nulty (Eds). Virus Infections of Birds (Elsevier Edit.), London. 
Lacroux, C., Andreoletti, O., Payre, B., Pingret J-L., Dissais A. \& Guerin, J-L. (2004). Pathology of spontaneous and experimental infections by Goose haemorrhagic polyomavirus. Avian Pathology, 33, 351-358.

Liu, S.S. \& Higgins, D.A. (1990). Yolk-sac transmission and post-hatching ontogeny of serum immunoglobulins in the duck (Anas platyrhynchos). Comparative Biochemistry and Physiology, 97B, 637-644.

Mató, T., Pénzes, Z., Rueda, P., Vela, C., Kardi, V., Zolnai, A., Misák, F. \& Palya V. (2009). Recombinant subunit vaccine elicits protection against goose haemorrhagic nephritis and enteritis. Avian Pathology, 38, 233-237.

Minke, J.M., Toulemonde, C.E., Dinic, S., Cozette, V., Cullinane, A. \& Audonnet, J. C. (2007). Effective priming of foals born to immune dams against influenza by a canarypox-vectored recombinant influenza H3N8 vaccine. Journal of Comparative Pathology, 137, Supplement 1:S76-80.

Mumford, J.A., Wilson, H., Hannant, D. \& Jessett, D.M. (1994). Antigenicity and immunogenicity of equine influenza vaccines containing a Carbomer adjuvant. Epidemiology and Infection, 112, 421-437.

Palya, V., Ivanics, E., Glavits, R., Dan, A., Mato, T. \& Zarka, P. (2004). Epizootic occurrence of haemorrhagic nephritis enteritis infections of geese. Avian Pathology, 33, 244-250.

Pingret, J-L., Boucraut-Baralon, C. \& Guérin, J-L. Goose haemorrhagic polyomavirus (GHPV) infection in ducks. 2008. The Veterinary Record, 162, 164.

Ritchie, B.W., Niagro, F.D., Latimer, K.S., Pritchard, N., Campagnoli, R.P. \& Lukert, P.D. (1996). An inactivated avian polyomavirus vaccine is safe and immunogenic in various Psittaciformes. Vaccine, 14, 1103-1107.

Schettler, C.H. (1977). Détection en France de la néphrite hémorragique et entérite de l'oie (NHEO). Recueil de Medecine Vetérinaire, 153, 353-355. 
Shah, K.V. (1996). Polyomaviruses. In: B.N. Fields, D.M. Knipe \& P.M. Howley (ed), Fields Virology, Third Edition (p. 2027-2043). Philadelphia: Lippincott-Raven Publishers.

Shah, K.V. (1998). Polyomavirus, infection and immunity. In Encyclopedia of immunology. Delves, P.J., Roitt, I.M. (eds). Harcourt Brace \& Company Publishers, pp. 1988-1990.

Shi, L., Ho, J., Norling, L.A., Roy, M. \& Xu, Y. (1999) A real-time quantitative PCR-based method for the detection and quantification of Simian virus 40. Biologicals. 27, 241252.

Soike, D., Kohler, B. \& Albrecht, K. (1999). A circovirus-like infection in geese related to a runting syndrome. Avian Pathology, 28, 199-202.

Steensels, M., Bublot, M., Van Borm, S., De Vriese, J., Lambrecht, B., Richard-Mazet, A., Chanavat-Bizzini, S., Duboeuf, M., Le Gros, FX. \& Van den Berg, T. (2009). Primeboost vaccination with a fowlpox vector and an inactivated avian influenza vaccine is highly immunogenic in Pekin ducks challenged with Asian H5N1 HPAI. Vaccine, 27, 646-654.

Vereecken, M., De Herdt, P., Ducatelle, R. \& Haesebrouck, F. (2000). The effect of vaccination on the course of an experimental Salmonella Typhimurium infection in racing pigeons. Avian Pathology, 29, 465-471.

Zielonka, A., Gedvilaite, A., Ulrich, R., Lüschow, D., Sasnauskas, K., Müller, H. \& Johne R. (2006). Generation of virus-like particles consisting of the major capsid protein VP1 of goose haemorrhagic polyomavirus and their application in serological tests. Virus Research, 120, 128-137. 


\section{Figure legends}

Figure 1a. ELISA antibody titres observed in goslings after vaccination with an Aluminium hydroxide-adjuvanted vaccine containing $10^{9} ; 10^{10} ; 10^{11}$ genomes (gen) per dose (5 birds in each group). Vertical bars represent standard deviation.

Figure 1b. ELISA antibody titres in goslings after vaccination using either the Aluminium hydroxide or Carbopol-adjuvanted vaccine (5 birds in each group). A group of 5 control, non-vaccinated birds was also included in the assay and did not show any detectable antibody during the experiment. Vertical bars represent standard deviation.

Figure 2. ELISA kinetics of GHPV-specific antibodies in groups of 15 growing geese vaccinated at day 0 with a boost at day 28, or non-vaccinated as controls. Vertical bars represent standard deviation. $(D=$ day of age $)$.

Figure 3. Comparison of ELISA titres of GHPV specific antibodies at day 56 post vaccination in breeder geese $(n=20)$, vitellus of eggs laid the same day $(n=10)$ and day-old-goslings $(n=20)$ hatched from eggs laid the same day. Vertical bars represent standard deviation.

Figure 4. ELISA titre kinetics of maternally derived antibodies in goslings hatched from vaccinated or non-vaccinated breeder geese ( $n=15$ birds in each group). The growth curve of vaccinated and control birds weighed throughout the study is included. Vertical bars represent standard deviation. ( $\mathrm{D}=$ day of age). 
Table 1. Virus challenge performed subcutaneously on day-old goslings hatched from either vaccinated or control breeders. Birds were daily monitored for clinical signs and were sampled at day 8 post inoculation for testing by GHPV PCR.

\begin{tabular}{lccc}
\hline Group of birds & $\begin{array}{c}\text { Virus challenge } \\
\text { at 1-day-old }\end{array}$ & $\begin{array}{c}\text { Total mortality } \\
\text { 20 days post-challenge }\end{array}$ & $\begin{array}{c}\text { GHPV cloacal excretion } \\
8 \text { days post-challenge }\end{array}$ \\
\hline $\begin{array}{l}\text { Goslings } \\
\text { hatched from } \\
\text { non- vaccinated } \\
\text { breeders (n=10) }\end{array}$ & $10^{7}$ genomes & $7 / 10^{\mathrm{a}}$ & $10 / 10^{\mathrm{b}}$ \\
$\begin{array}{l}\text { Goslings } \\
\text { hatched form } \\
\text { vaccinated } \\
\text { breeders (n=15) }\end{array}$ & $10^{7}$ genomes & $0 / 15$ & $0 / 15$ \\
$\begin{array}{l}\text { Goslings } \\
\text { hatched from } \\
\text { non- vaccinated } \\
\text { breeders }(\mathrm{n}=5)\end{array}$ & None & & \\
\hline
\end{tabular}

${ }^{\text {a }}$ Number dead/ number in group.

${ }^{\mathrm{b}}$ Number of PCR-positive birds/ number in group. 


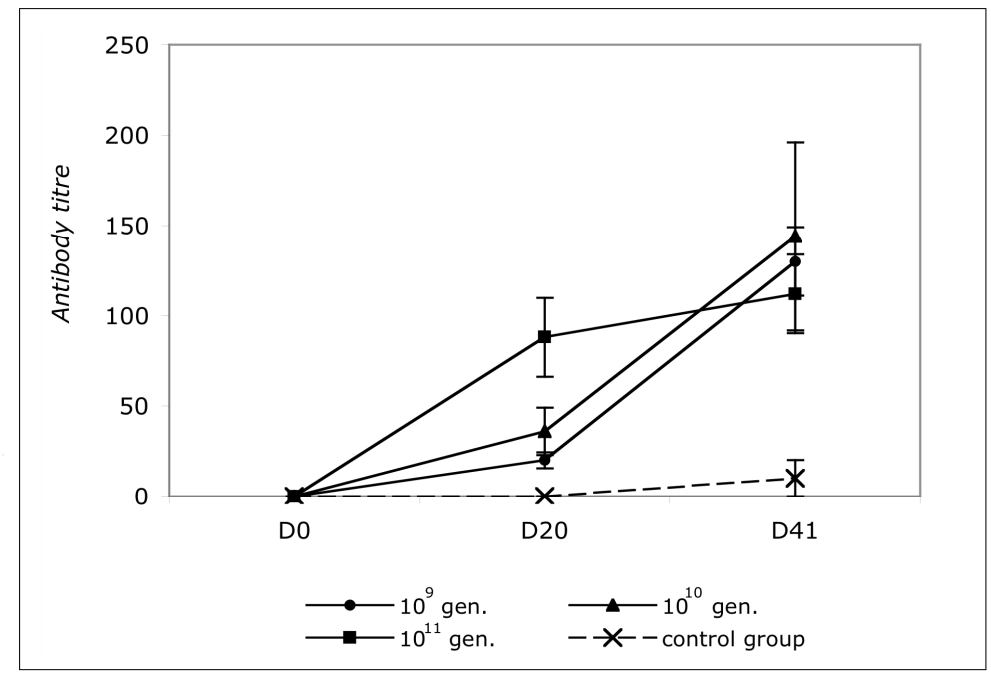

Figure 1a. ELISA antibody titres observed in goslings after vaccination with an Aluminium hydroxide-adjuvanted vaccine containing $10^{9} ; 10^{10} ; 10^{11}$ genomes (gen) per dose (5 birds in each group). Vertical bars represent standard deviation.

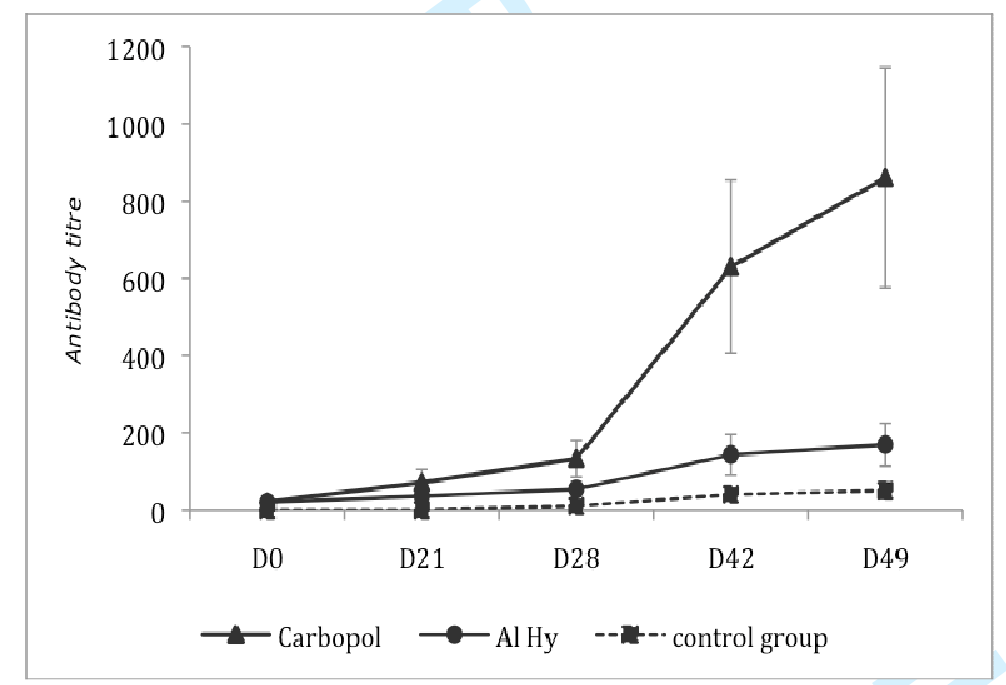

Figure 1b. ELISA antibody titres in goslings after vaccination using either the Aluminium hydroxide or Carbopol-adjuvanted vaccine (5 birds in each group). A group of 5 control, non-vaccinated birds was also included in the assay and did not show any detectable antibody during the experiment. Vertical bars represent standard deviation. 


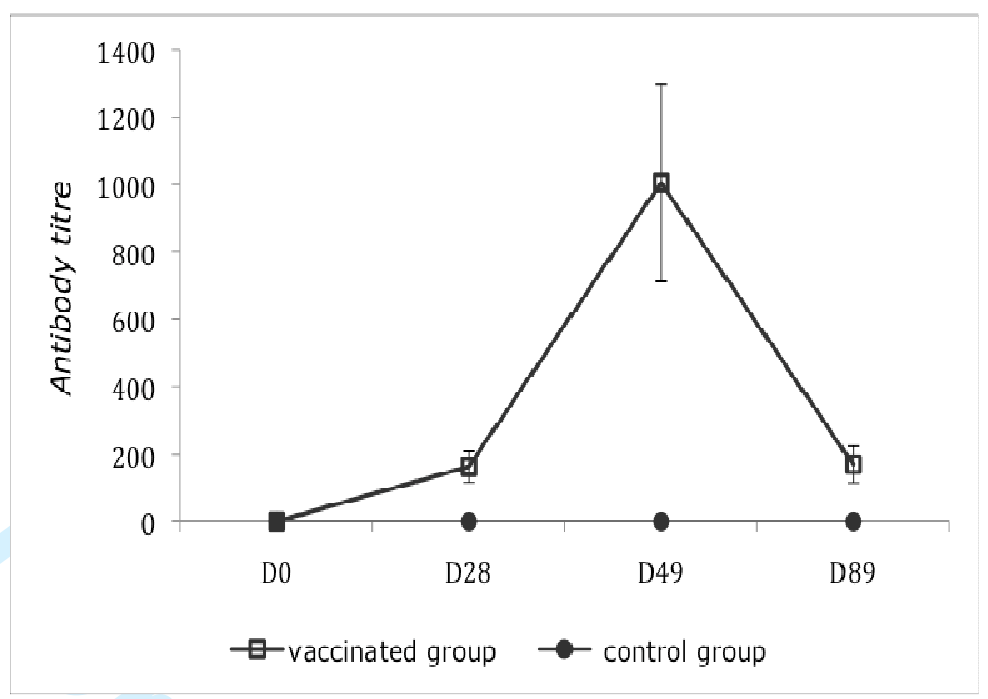

Figure 2. ELISA kinetics of GHPV-specific antibodies in groups of 15 growing geese vaccinated at day 0 with a boost at day 28, or non-vaccinated as controls. Vertical bars represent standard deviation. $(D=$ day of age $)$

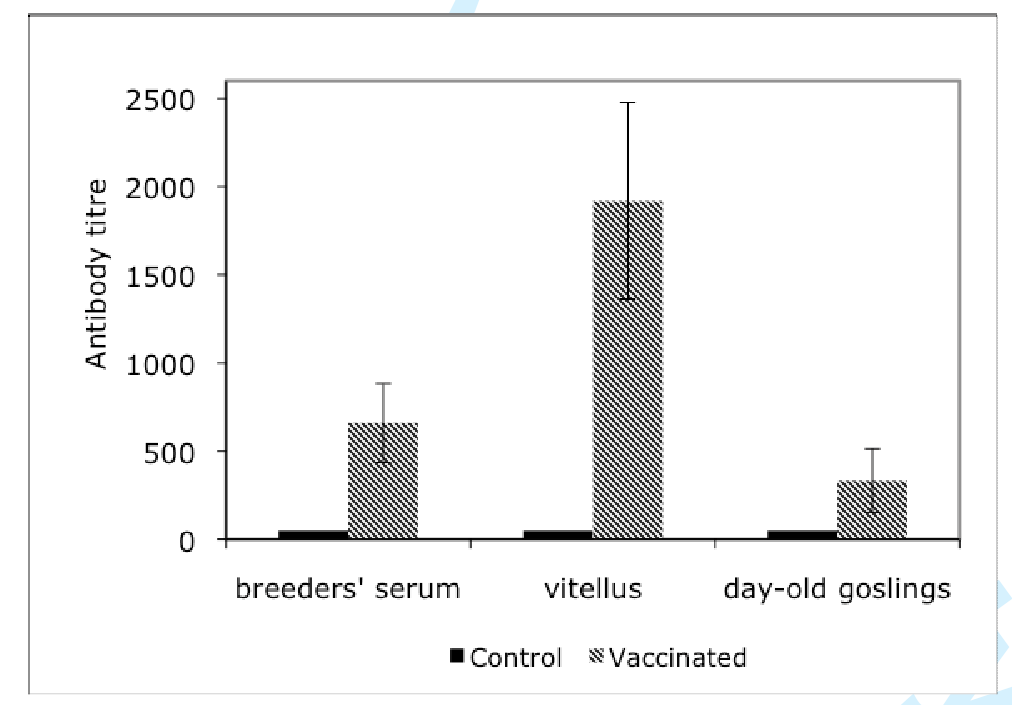

Figure 3. Comparison of ELISA titres of GHPV specific antibodies at day 56 post vaccination in breeder geese $(n=20)$, vitellus of eggs laid the same day $(n=10)$ and day-old-goslings $(n=20)$ hatched from eggs laid the same day. Vertical bars represent standard deviation. 


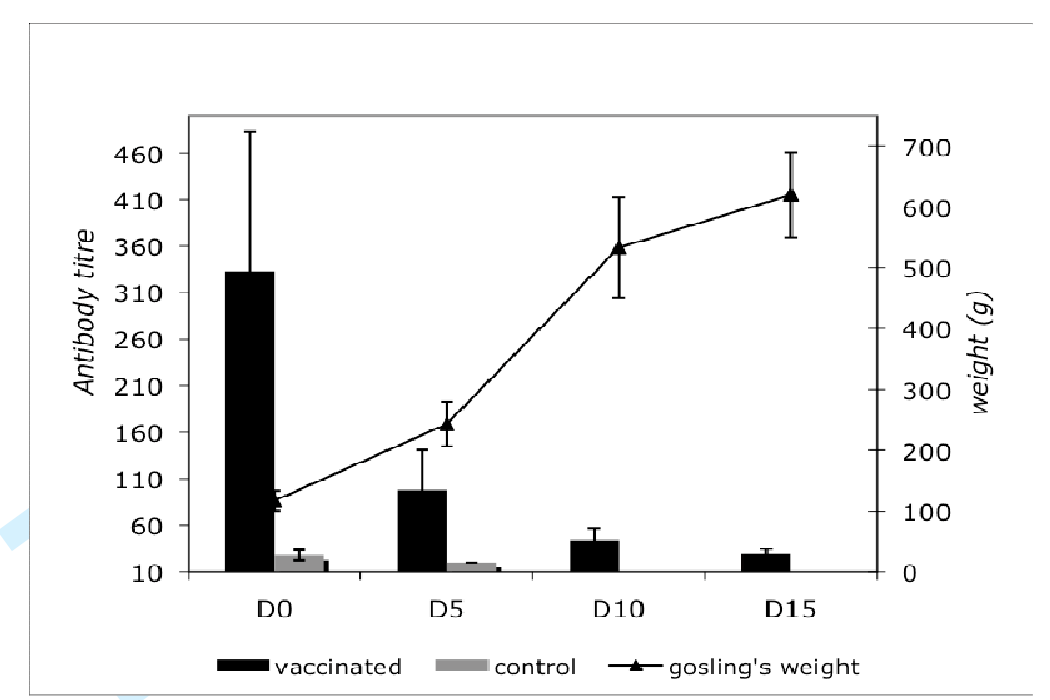

Figure 4. ELISA titre kinetics of maternally derived antibodies in goslings hatched from vaccinated or non-vaccinated breeder geese ( $n=15$ birds in each group). The growth curve of vaccinated and control birds weighed throughout the study is included. Vertical bars represent standard deviation. ( $\mathrm{D}=$ day of age). 